\title{
Shifting Micro-Enterprises into the Cloud: Guidelines for Cloud Service Providers
}

\author{
Raoul Hentschel \\ TU Dresden \\ raoul.hentschel@tu-dresden.de
}

\author{
Katja Bley \\ TU Dresden \\ katja.bley@tu-dresden.de
}

\author{
Hendrik Schön \\ TU Dresden \\ hendrik.schoen@tu-dresden.de
}

\begin{abstract}
Cloud computing is a driving force in digitalization, and it promises companies benefits such as lower entry costs, greater flexibility/scalability, and cost savings compared to traditional IT solutions. Such benefits can also be valuable for microenterprises. However, many of these small businesses do not have access to the necessary know-how and resources to select, implement, and operate cloud technologies. As sources of these technologies, cloud service providers play a crucial role in this context as it is their business strategy that can support and convince micro-enterprises to adopt cloud technologies. As the class of micro-enterprises and the role of cloud service providers has been largely ignored in recent research, we conducted a quantitative study on the cloud computing user behavior of micro-enterprises in Germany. Based on our findings, we derived guidelines and recommendations for cloud service providers concerning the adaptation of their business strategies to adequately address the needs of micro-enterprises.
\end{abstract}

\section{Introduction}

Cloud computing (CC) is a driving force for digital transformation, and it promises companies of all sizes benefits such as the flexible use of computing resources, e.g., servers, storage, networks, applications, and services. It is characterized by low/minimum entry costs, variable payment models, as well as greater flexibility and scalability $[1,2]$. While larger companies began to benefit from the advantages of $\mathrm{CC}$ at an early stage [3], a growing number of small and medium-sized enterprises (SME) are learning that using cloud services creates economic and operational advantages and thereby have a great deal of potential [1]. Almost $93 \%$ of all European companies currently employ fewer than ten people and thus belong to the class of micro-enterprises (ME) [4]. However, unlike larger enterprises, MEs often do not have access to the necessary know-how and resources to select, implement, and maintain complex information and communication technology (ICT) or the (financial) capabilities to set up and operate their own IT departments $[2,5]$. This leads to a state of ambivalence for MEs. On the one hand, they are limited by a lack of resources in dealing with complex ICT innovations in their business models. On the other hand, they are forced by ongoing information technology innovations to digitize their business units in order to keep their processes efficient and remain competitive.

CC technologies offer a possible solution to this bottleneck. Pricing models like pay-per-use transform investment costs into variable costs and thus reduce the capital commitment of companies [6]. Also, the scope of sourced IT services can be scaled as needed as only actually used units are charged. Consequently, IT costs only increase in relation to the resources required [5]. However, despite these advantages, MEs are still hesitant about using CC technologies. One of the key players in this context is the cloud service provider (CSP). CSPs play a crucial role when it comes to the adoption of $\mathrm{CC}$ technologies in MEs and their decision for or against a CC solution. It is up to a CSP to respond to the needs of the MEs and to meet their specific demands and solve their problems in order to address this large customer group and create incentives for them. However, since the class of MEs still lacks adequate representation in research $[7,8,9]$, the possibilities for CSPs to improve their business strategies in addressing MEs remain limited.

We address this gap between the needs of MEs for the adoption of CC and the related implications for the CSP business model in our research by following a twofold research approach. In the first step, we determine the scope in which MEs are already using 
$\mathrm{CC}$ in practice as well as their motivational factors for and against the application of cloud technologies. Hence, the first research question (RQ1) is stated as, What is the status of the adoption of cloud computing in MEs? Based on these findings, we used an inductive research approach to derive guidelines for CSPs for adapting their business strategies to address MEs' specific challenges. Therefore, the second research question (RQ2) is stated as, What guidelines can be derived for a cloud service provider's business strategy to adequately address the ME's needs?

The remainder of this paper is structured as follows. First, in Section 2, the theoretical background including the concepts of CC and MEs is described. We present our research approach in Section 3, consisting of an online survey and the method for deriving guidelines for CSPs. Next, Section 4 presents the results of the quantitative study of MEs' CC usage. In Section 5, we derive and discuss the guidelines and recommendations for CSPs concerning the study results. The paper is concluded with a summary and proposal for future work in Section 6.

\section{Theoretical background}

\subsection{Cloud computing}

As a new method of IT sourcing, CC allows companies to gain access to a shared pool of managed and scalable IT resources on a rental basis (e.g., payper-use, pay-per-period). The resources (e.g., networks, servers, storage, applications, services) are offered in a scalable way via the internet without the need for any long-term capital expenditures or specific IT knowledge on the customer side $[2,10,11]$. CC represents a transformational shift in IT that is rapidly changing the way in which organizations manage and deliver IT services over the internet. Especially in the IT departments of large organizations, but also in SMEs, CC has become an everyday phenomenon [12].

Adopting cloud services can also benefit MEs by allowing employees to focus on value-added activities and relieving their workload by transferring technical responsibility to the CSP [13]. Small companies especially gain access to state-of-the-art technologies and standards without having to concern themselves with development, maintenance, and operation [14]. These technologies would otherwise remain obscure to this class of companies.

The literature on CC presents a wide-ranging set of factors that affect organizations' decisions about adopting CC services. Schneider and Sunyaev [1] found strong evidence that cost savings, accessibility to IT resources, flexibility, quality improvements, reduced time to market, top management support, and vendors' service capabilities (i.e., expertise and knowledge about technology and processes, technical and managerial IT skills, and reputation as perceived by the customer) had a positive effect on $\mathrm{CC}$-sourcing decisions. A further study confirmed both the positive impact of perceived benefits, i.e., support from top management and the expertise and reputation of the CSPs, and the negative impact of complexity and perceived risks on the acceptance of CC [15]. CC services are typically classified by the type of service differentiated by the resource used (e.g., according to application [SaaS], platform [PaaS] and infrastructure [IaaS] levels) [16]: IaaS provides low-level infrastructure such as virtual machines; PaaS provides a platform for developing enterprise systems, and SaaS delivers entire web applications.

\subsection{Micro-enterprises}

Although they play a crucial role in the macroeconomic context, MEs are often not considered separately in business classifications or scientific research, as they are included in the international definition of small and medium-sized enterprises. According to the European definition, the grouping of SMEs ranges from one to fewer than 250 employees and up to 50 million euros revenue per year [17]. However, the number of employees and the yearly turnover of a micro-enterprise are far below this classification (see Table 1).

Table 1: SME structural data overview in Germany 2018 [18]

\begin{tabular}{|l|c|c|c|}
\hline $\begin{array}{l}\text { Company } \\
\text { category }\end{array}$ & $\begin{array}{l}\text { No. of } \\
\text { ent. }\end{array}$ & $\begin{array}{l}\text { No. of } \\
\text { emp. }\end{array}$ & $\begin{array}{l}\text { Revenue } \\
\text { [€ billion] }\end{array}$ \\
\hline $\begin{array}{l}\text { Micro- } \\
\text { enterprises } \\
(1-9 \text { emp. })\end{array}$ & $\begin{array}{c}2,126,967 \\
(81.78 \%)\end{array}$ & $\begin{array}{c}5,721,920 \\
(18.39 \%)\end{array}$ & $\begin{array}{l}453,407 \\
(6.64 \%)\end{array}$ \\
\hline $\begin{array}{l}\text { Small } \\
\text { enterprises } \\
(10-49 \text { emp. })\end{array}$ & $\begin{array}{c}392,298 \\
(15.08 \%)\end{array}$ & $\begin{array}{c}6,890,040 \\
(22.14 \%)\end{array}$ & $\begin{array}{c}769,758 \\
(11.27 \%)\end{array}$ \\
\hline $\begin{array}{l}\text { Medium-sized } \\
\text { enterprises }\end{array}$ & 65,921 & $5,202,654$ & 835,347 \\
$(50-249$ emp.) & $(2.53 \%)$ & $(16.72 \%)$ & $(12.23 \%)$ \\
\hline $\begin{array}{l}\text { Large } \\
\text { enterprises } \\
(>249 \text { emp. })\end{array}$ & 15,769 & $13,306,226$ & $4,771,891$ \\
$(0.61 \%)$ & $(42.76 \%)$ & $(69.86 \%)$ \\
\hline
\end{tabular}

Consequently, there are wide-ranging and, most of all, strategically and economically relevant differences in the group of micro-enterprises compared to larger enterprises within this SME classification. Typical characteristics are less than ten employees and a turnover of less than two million euros per year. 
Consequently, the investment volume of this group of companies is relatively low, but in order to remain competitive, MEs need to adapt to current trends and developments.

The combined responsibility for these strategic and financial decisions lies with the owner, which is why this position often requires knowledge of a wide range of business processes. Furthermore, the selection, implementation, and operation of IT solutions requires a great deal of time, effort, and expertise; however, these are generally performed by the managing director or one of the employees who has basic IT knowledge, but no qualified IT background in handling complex technologies [16]. In addition, the person responsible for IT cannot focus on his or her core competencies during this time, which results in high opportunity costs.

Consequently, technical expertise within MEs is often limited, and crucial knowledge of digital transformation processes and the respective advantages is still not evident in MEs [19]. Therefore, we argue that MEs seem predestined to the use of cloud services. However, existing studies largely focus on the adoption of cloud services in large or medium-sized enterprises. The group of MEs is rarely represented in these studies, which is why we focus on this class of enterprises. Only if these companies are considered separately and their specific needs are identified will CSPs be able to respond by adapting their business strategies [20].

\section{Research approach}

The research approach we followed is twofold. Initially, we conducted a quantitative study based on the results of a literature review to identify the current status of adoption and application of CC in MEs, as well as motivational factors in favor of and against the use of CCs. We then followed an inductive approach to derive guidelines and recommendations for CSPs in order to provide an advanced product portfolio that is adapted to the specific needs and requirements of the class of MEs.

\subsection{Quantitative study}

We conducted a literature review to investigate whether there are studies addressing the topic of CC adoption and the most important motivational factors for the adoption of CC in MEs in Germany. In the relevant literature, we searched for studies with keywords concerning $\mathrm{CC}$ and MEs. In addition to technical journals and journals ranked $\mathrm{A}$ and $\mathrm{A}+$, we also examined the database of the German Federal
Statistical Institute for corresponding surveys on the topic. Table 2 provides an overview of selected studies identified by various institutions that either examine the general approach of companies to cloud computing or contain subsections with questions on specific aspects of cloud usage in enterprises of different sizes in the respective surveys. Since the topic we are investigating is a field of research with a high level of practical relevance, the study results we found are largely surveys of private commercial enterprises.

Although the focus here is on German enterprises, a general tendency can be derived: as a group of companies, MEs are perceived at most as a marginal group and are not fully investigated in the research.

Table 2: Overview of selected studies of cloud use in enterprises of different sizes

\begin{tabular}{|c|c|c|}
\hline Author/Year & $\begin{array}{l}\text { No. of surveyed } \\
\text { companies by } \\
\text { number of } \\
\text { employees }\end{array}$ & \\
\hline $\begin{array}{l}\text { KPMG \& } \\
\text { Bitkom, } \\
2018[8]\end{array}$ & $\begin{array}{l}20-99 \text { emp.: } 28 \\
100-1,999 \text { emp.: } 189 \\
>1,999 \text { emp.: } 340\end{array}$ & $\begin{array}{l}\text { MEs not } \\
\text { considered at all }\end{array}$ \\
\hline $\begin{array}{l}\text { McAfee, } 2018 \\
{[21]}\end{array}$ & $\begin{array}{l}501-1,000 \text { emp.: } 350 \\
1.001-5.000 \text { emp.: } \\
350 \\
>5,000 \text { emp.: } 700\end{array}$ & $\begin{array}{l}\text { MEs not } \\
\text { considered at all }\end{array}$ \\
\hline $\begin{array}{l}\text { Capgemini, } \\
2018 \text { [22] }\end{array}$ & $\begin{array}{l}\text { Revenue focus } \\
\text { Smallest category: }<50 \\
\text { mil. revenue }\end{array}$ & $\begin{array}{l}\text { Initial } \\
\text { classification of } \\
>50 \text { mil. } € \text { too } \\
\text { high for MEs }\end{array}$ \\
\hline $\begin{array}{l}\text { KPMG \& } \\
\text { Bitkom, } \\
2017[23]\end{array}$ & $\begin{array}{l}20-99 \text { emp.: } 183 \\
100-499 \text { emp.: } 183 \\
500-1,999 \text { emp.: } 144 \\
\geq 2,000 \text { emp.: } 44\end{array}$ & $\begin{array}{l}\text { MEs not } \\
\text { considered at all }\end{array}$ \\
\hline $\begin{array}{l}\text { German Federal } \\
\text { Statistical } \\
\text { Office, } 2016 \\
\end{array}$ & $\begin{array}{l}20,000 \text { companies } \\
\text { contacted, mostly } \\
>250 \text { emp. }\end{array}$ & $\begin{array}{l}\text { MEs not } \\
\text { considered } \\
\text { directly }\end{array}$ \\
\hline
\end{tabular}

Accordingly, to date we have not been able to find any study in the literature investigating the $\mathrm{CC}$ behavior of MEs. Based on this result, following an exploratory research design and conducting an online interview study with a focus on the adoption of $\mathrm{CC}$ in MEs, we were able to define specific needs and, derived from these, recommendations for ways CSP can address this group of companies. Therefore, not only companies already using CC (usually known as "cloud consumers" or "cloud users"), but also companies not currently using CC (regarded as "cloud non-users") and companies that avoid adopting cloud services (referred to as "cloud resisters") were surveyed.

We conducted several pre-tests with various researchers from the respective research fields as well as a small sample of practitioners, and we subsequently adjusted the questionnaire accordingly. 
The final version was initially sent to 5,000 MEs randomly selected from a German company database. In addition, a link to the online survey was distributed in respective groups of the professional network "Xing," in which cloud computing is discussed.

\subsection{Deriving guidelines and recommendations}

The aim of the paper is to determine the current status of CC adoption in MEs as well as to inductively derive recommendations and guidelines for CSPs in order to adapt their current business strategies according to MEs' specific needs. Furthermore, we divided the business strategy of a CSP into three phases - pre-adoption, adoption, and post-adoptionadapting the characteristics of each phase from Schneider and Sunyaev [24]. The pre-adoption phase consists of the requirements determination (e.g., list of requirements, selection criteria) that incorporates the user's decision about whether and to what extent a cloud service will be used. This phase also includes acquisition, i.e., the evaluation and selection decisions of cloud providers and services. The adoption phase is dedicated to the integration of services; it includes activities such as customization, configuration, and integration into the consumer's IT landscape. The post-adoption phase begins after the cloud service is integrated and implemented in operational use (contract fulfillment). On the customer side, this includes service usage and monitoring activities. On the provider side, this phase includes maintenance, support, and billing activities. Additionally, retirement is also part of the post-adoption phase, i.e., the phaseout of a cloud service. This occurs, for example, if the CSP discontinues the service or if the cloud consumer switches to another provider.

We chose this phase distinction to transfer the process of CC selection, implementation, and support on the ME's side to the business strategy of the CSP. By considering the $\mathrm{CC}$ adoption challenge from the perspective of the MEs, it is possible for a CSP to provide the appropriate support at the right timebefore, during, or after the adoption of cloud services. By providing these recommendations, which are based on the data and results of our study, we are able to derive more generally applicable guidelines for CSPs to address these issues. In our understanding, a guideline is an abstraction of action recommendation(s) on a meta-level that can be instantiated in a CSP's business strategy (see Figure 1).

In formulating these guidelines, we follow the rigorous approach of Design Science Research (DSR) $[25,26]$, the goal of which is the development of design knowledge on different levels of abstraction, e.g., constructs, models, methods, design principles, and design theories $[27,28]$. In the formulation of our guidelines for the design of a business strategy, we are guided by generally applicable approaches that also apply to the derivation of design principles. According to Van Aken [29], a meta-design principle is defined as follows: "If you want to achieve $\mathrm{Y}$ in situation $\mathrm{Z}$, then something like action $\mathrm{X}$ will help." This principle can be transferred to our research. Given the actual equipment and adoption behavior of the MEs (Z), the goal (Y), which is pursued by the recommendation for action (X), can be generated by the latter. Nevertheless, our guidelines do not claim to have the same abstract scope of validity of design principles as those according to DSR. For example, our guidelines do not generate the abstract design knowledge included in design theory [30].

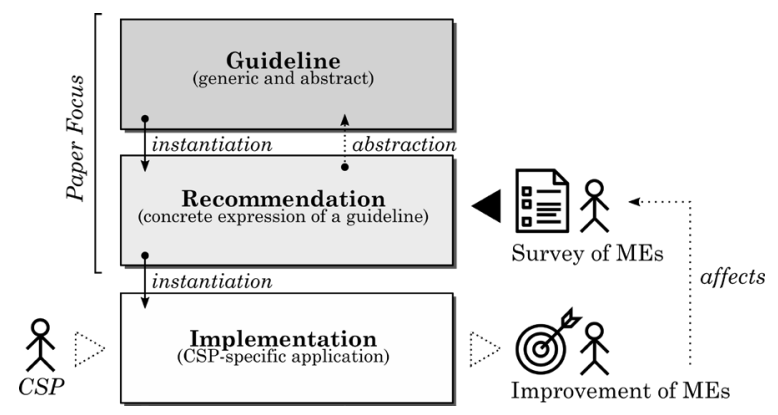

Figure 1: Guidelines as abstractions of recommendations (meta guidelines)

However, they do fulfill the purpose demanded by Hevner et al. [25], that design principles - in our case, guidelines-should make results accessible to the technology- and management-oriented audience, and that they are clearly prescriptive. Also, MEs compose such a large category of companies that the scope of the guidelines is large enough to address a problem class and not an individual problem.

\section{Findings}

\subsection{Structure and sample statistics of MEs}

For the analysis of our survey, a total of 278 questionnaires were returned fully answered. Fortyseven percent of the participating companies employ 6-10 employees, $42 \%$ 2-5 employees, and $11 \%$ of the companies are single-person enterprises. In most of the surveyed companies $(85 \%, n=276)$, the owner/manager is responsible for the selection of IT solutions or is at least involved in the decision-making process. Consequently, only $15 \%$ of the owners or managing directors delegate the selection responsibility completely to employees or external 
service providers with higher technical competence. Also, the operation (e.g., maintenance) of IT is supported by the managing director in at least $50 \%$ of the companies. Accordingly, the situation in which the managing director is responsible for both the selection and the operation of the IT solution is the most frequent combination (47.8\%). In only $23.5 \%$ of the companies is the IT operation performed by qualified internal employees, whereas $45 \%$ of the companies delegate the responsibility for IT operation to external service providers. To obtain comprehensive findings, selected results were compared with corresponding values from existing cloud studies (see Table 2) conducted with enterprises of different sizes.

\subsection{General cloud computing adoption and usage behavior}

Cloud users, cloud planners, and non-users: More than $55 \%$ of all MEs are already using cloud services, while $4 \%$ are planning to use the cloud in the future. However, $24.5 \%$ of the companies have made a deliberate decision against the use of CC. The term "cloud resisters" is used as a synonym for these participants who are not (yet) willing to adopt cloud services.

Furthermore, $16 \%$ of the companies are either unacquainted with the technology, or the cloud does not play a relevant role in their IT organization or strategy. The age of the company plays an important role in the affinity for cloud adoption. Of MEs in existence not more than five years, $75.9 \%$ are using $\mathrm{CC}$; among companies in existence for more than ten years, the proportion is only 45.7 percent. A higher

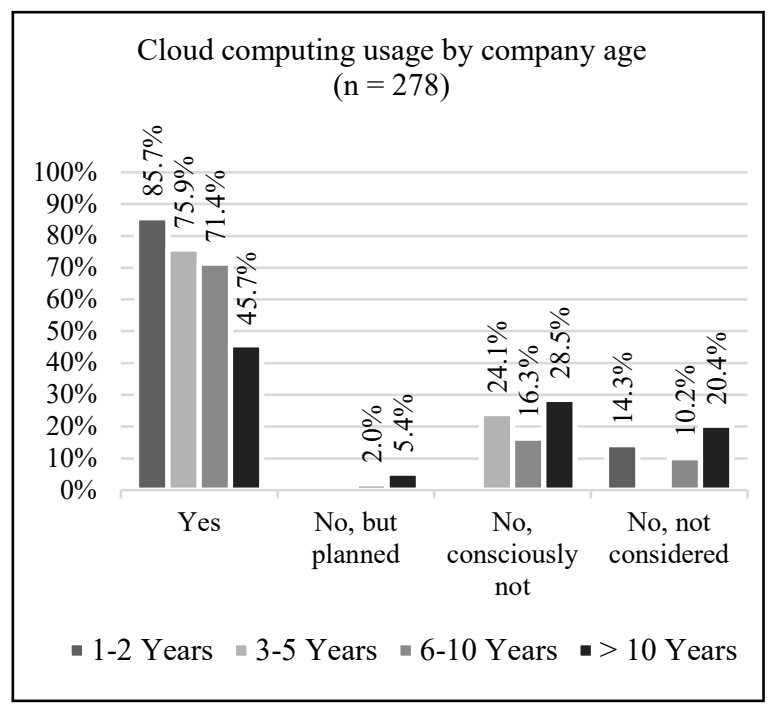

Figure 2: Cloud computing usage by company age proportion (48.9\%) of this group has decided against using cloud services. This skeptical perception of the technology is reflected in the high number of cloud resisters in this company age group. Figure 2 shows the percentages of companies using $\mathrm{CC}$ technologies broken down by the age of the companies, regardless of the service models IaaS, PaaS, and SaaS. The age of the company seems to reinforce this effect since all statements came from companies in existence for over ten years.

Table 3: Cloud usage according to the cloud service model

\begin{tabular}{|c|c|c|c|c|c|c|}
\hline \multirow{2}{*}{ 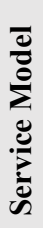 } & \multicolumn{3}{|c|}{ Cloud Users } & \multicolumn{3}{|c|}{ Cloud Planners } \\
\hline & $\stackrel{v}{2}$ & $\frac{\mathfrak{s}}{\mathfrak{\Xi}}$ & $z$ & $\approx$ & $\underset{\mathfrak{Z}}{\mathfrak{s}}$ & $i$ \\
\hline $\begin{array}{l}\text { त् } \\
\text { ஸू }\end{array}$ & $\begin{array}{c}117 \\
(76 \%)\end{array}$ & $\begin{array}{c}5 \\
(3.2 \%)\end{array}$ & $\begin{array}{c}\mathbf{2 9} \\
(18.8 \%)\end{array}$ & - & $\begin{array}{c}\mathbf{4} \\
(36.3 \%)\end{array}$ & $\begin{array}{c}\mathbf{5} \\
(45.5 \%)\end{array}$ \\
\hline స్త్ర & $\begin{array}{c}\mathbf{1 2 5} \\
(81.2 \%)\end{array}$ & $\begin{array}{c}\mathbf{5} \\
(3.2 \%)\end{array}$ & $\begin{array}{c}\mathbf{2 3} \\
(14.9 \%)\end{array}$ & - & $\begin{array}{c}\mathbf{8} \\
(72.7 \%)\end{array}$ & $\begin{array}{c}\mathbf{3} \\
(27.3 \%)\end{array}$ \\
\hline జ్ల & $\begin{array}{c}53 \\
(34.4 \%)\end{array}$ & $\begin{array}{c}\mathbf{4} \\
(2.6 \%)\end{array}$ & $\begin{array}{c}77 \\
(50.0 \%)\end{array}$ & - & $\begin{array}{c}\mathbf{3} \\
(27.3 \%)\end{array}$ & $\begin{array}{c}\mathbf{2} \\
(18.2 \%)\end{array}$ \\
\hline \multicolumn{7}{|c|}{ Cloud users: $\mathrm{n}=154 ;$ Cloud planners: $\mathrm{n}=11$} \\
\hline
\end{tabular}

Cloud service models: Examining cloud adoption according to the service model in MEs (see Table 3), the following results emerge. The majority of MEs $(>80 \%)$ use IaaS, i.e., a scalable cloud infrastructure. In addition to the 125 companies already using IaaS, 13 additional companies are planning to use IaaS services. PaaS is used by $34.4 \%$ of MEs that already use cloud services, with almost 30\% (15 responses) from the information and communications sector. An additional $22.6 \%$ (12 responses) came from the retail industry. The benefits of employing ready-to-use development environments and tools enable PaaS developers to focus on the quality of the core development. MEs from the information and communication sector can thus develop high-quality applications without having to set up their own IT infrastructure. Also, trading companies whose business activities require a strong customer-oriented focus can rely on pre-configured components and tools from CSPs and thus create customer-friendly web applications without extensive experience in software development [31].

SaaS services (e.g., sourcing ready-to-use software from the cloud), which account for most business applications, are used by more than $75 \%$ of 


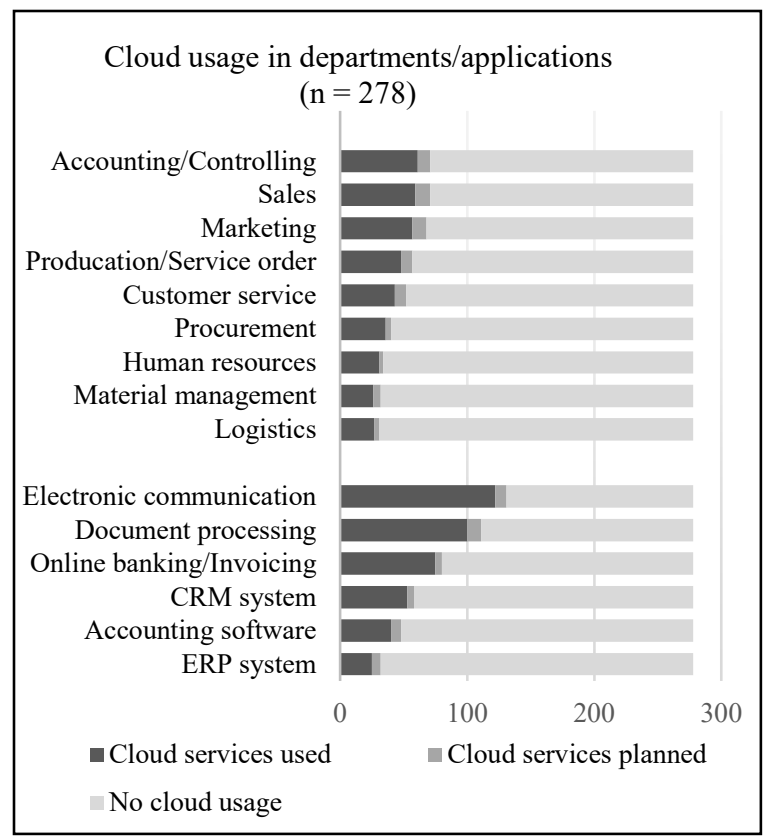

Figure 3: Cloud usage in departments and application areas

cloud users $(\mathrm{n}=154)$. Table 3 shows the distribution in relation to the respective cloud service models.

Cloud adoption in business departments: An analysis of the surveyed MEs using cloud services indicates that accounting and controlling are the departments most frequently supported by cloud services $(22 \%, 61$ responses). As a significant portion of the data collected in the context of controlling contains sensitive information, it can be assumed that the resulting benefits exceed the existing security concerns. Cloud services are also frequently used for sales and marketing. These departments are often bundled by CSPs as "salesforce" and integrated into a complete software solution that enables companies to create and manage their marketing and sales channels and customer relations automatically, i.e., in real time and efficiently [32].

Figure 3 shows, in addition to the business areas supported by cloud services, what types of cloud solutions are mainly used.

Electronic communication (e.g., e-mail, calendar services, etc.) are the most frequently used applications (almost 44\%, 122 responses). It was surprising that in this category the reported usage was higher than the reported usage of SaaS services (76\% in Table 3). This indicates that the term "SaaS," despite well-known examples (e.g., Microsoft 365, Google Docs), caused comprehension problems among some of the survey participants, and/or the participants encountered problems with the classification. Apparently, some of the MEs misunderstood the definition of $\mathrm{CC}$ and related technologies. Furthermore, almost $36 \%$ of all MEs stated that word and document processing activities supported by cloud solutions (e.g., permanent access to documents such as offering drafts in spreadsheet applications) are of high relevance. However, this is lower than the comparative proportion of $46 \%$ determined in the study of KPMG, in which companies with 20 or more employees were surveyed [23]. For larger companies, the availability of text and document processing via cloud services is thus more common than in MEs. Enterprise resource planning (ERP) systems are supported by cloud solutions in less than $10 \%$ of all MEs. In contrast, 32\% of larger companies use cloud services for ERP systems [23]. In the sector of human resources, only $11.2 \%$ of MEs use cloud solutions.

\subsection{Motivational factors for the adoption of cloud services}

In investigating the motivational factors that convince MEs to use CC technologies, we found that the most widely accepted basis for MEs adopting cloud services is the ability to access data from any location and any device. Working while mobile or

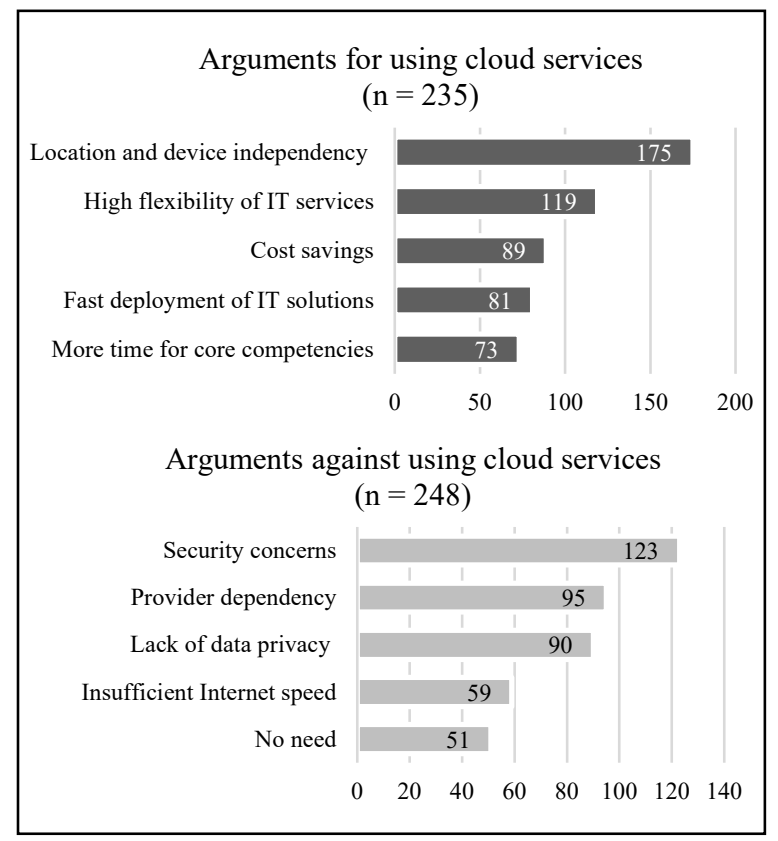

Figure 4: Arguments for and against using cloud services

from a home office as well as synchronization of data (e.g., reports, contracts) from customer meetings in real time are of the highest relevance for $75 \%$ of all MEs (175 responses). MEs with large workloads are often under time pressure [33], and location- 
independent access to documents combined with faster implementation of IT solutions and the possibility of focusing on core competencies address these time bottlenecks. The economic and organizational aspects of the scalability of the adopted services (119 responses) and the resulting cost savings (89 responses) through usage-based payment models were further key factors in the decision to adopt cloud services. In contrast, higher performance and data security standards were named by only $28 \%$ and $25 \%$ of the respondents, respectively. There are two possible reasons for this: these aspects could be of only minor importance for MEs (this is unlikely as security concerns regarding outsourced data are the main reasons against using cloud services; see Figure 4), or there could be a lack of trust in CSPs.

As a result, the actions performed by CSPs (e.g., service-level agreements [SLAs] and certifications) to ensure availability, performance, and data security are not sufficiently communicated or are too complex to convince MEs to use cloud services.

\subsection{Obstacles to the adoption of cloud services}

Among the arguments against using cloud services, concerns about lack of data security and data privacy are the most important barriers. Approximately $50 \%$ of the responding companies (123 responses) mentioned these concerns as a negative aspect (see Figure 4). Vendor lock-in is also an important factor preventing MEs from using cloud services $(38.3 \%)$. For example, uncertainty can result from increasing prices or changes to agreements that cannot be declined because migration to another cloud provider would seriously impact the daily operations of the business. Furthermore, insecurities regarding data privacy, especially due to the revision of the General Data Protection Regulation (GDPR), were mentioned by $36.3 \%$ (90 respondents) as another important argument against the use of cloud services. Another obstacle mentioned by several participants is that there are too many cloud services and functionalities on the market, and they are too nontransparent to maintain an overview of required and relevant services.

Insufficient internet speed was mentioned as a further obstacle to adopting cloud services. Nationwide broadband internet coverage is one of the main requirements for governments to ensure the future competitiveness of the economy through unhindered use of digital technologies.

Finally, 20.6\% (51 respondents) concluded that there was no need to use cloud services in their companies. As for companies that intentionally avoid adopting cloud services, so-called cloud resisters $(n=62,54.8 \%)$, they see no reason for using cloud services at all. After security concerns, this is the second most important obstacle for this group of respondents. In contrast to all survey participants, a significantly higher percentage of cloud resisters ( $27.4 \%$ compared to $18.1 \%$ ) have concerns about the expanding integration of cloud services into existing IT structures.

\section{Discussion}

We structured our analysis according to the challenges mentioned by MEs and divided them into phases of business initiation (pre-adoption), implementation and integration (adoption), and IT operation and retirement (post-adoption). We identified 13 issues that match the MEs' challenges and formulated respective recommendations for CSPs.

For each recommendation, we further identified the affected phase, the targeted group of CC users (non-users, users, and resisters), as well as examples of possible implementations for CSPs. A guideline represents a synthesis of several recommendations that address similar challenges and/or phases and can thereby be regarded as a meta-recommendation for the design of a CSP's business strategy (see Table 4).

The first guideline focuses on the challenge of the extensive and dynamic market of $\mathrm{CC}$ and the bundling of IT responsibility in the owner of an ME. The variety of available cloud services is complicated by a lack of information transparency concerning product characteristics, technology, QoS, pricing, and their intercorrelations (e.g., price/quality trade-offs). This makes it difficult for MEs to evaluate, compare, and select services. Therefore, CSPs should address these issues in an early stage of the pre-adoption phase by providing adequate and comprehensive information (e.g., using simple terminology, reducing technical terms, etc.) to non-users.

The second guideline combines the challenges of providing data security and transparency as well as prioritized addressing of non-users and cloud resisters. To counteract the concerns of this group regarding $\mathrm{CC}$, trust-building instruments are necessary. These include extensive pre-sales support with webinars, workshops, and free trials of the offered service, but it also includes stronger communication of applied (security) measures and procedures. Finally, references to the positive service experiences of existing cloud consumers that demonstrate the benefits of CC can be useful.

The challenge of ongoing services and operational support for MEs is considered in guideline three. Support for the integration of selected services in existing IT infrastructure is highly relevant in the 
Table 4: Guidelines and related recommendations from identified challenges of MEs

\begin{tabular}{|c|c|c|c|c|}
\hline Challenge(s) & Recommendation for CSPs & $\begin{array}{l}\text { Related } \\
\text { Phase(s) }\end{array}$ & $\begin{array}{c}\text { Target } \\
\text { Group(s) }\end{array}$ & $\begin{array}{l}\text { Implementation } \\
\text { Examples }\end{array}$ \\
\hline \multicolumn{5}{|c|}{ Guideline 1: Provide adequate and comprehensible information to facilitate the selection of cloud services } \\
\hline \multirow{3}{*}{$\begin{array}{l}\text { Dynamic market: } \\
\text { Market of cloud } \\
\text { services is } \\
\text { extensive/complex and } \\
\text { covers a variety of } \\
\text { different possible } \\
\text { applications } \\
\text { IT responsibility: } \\
\text { Owner/manager is } \\
\text { solely responsible for } \\
\text { IT solutions }\end{array}$} & $\begin{array}{l}\text { (R1.1) Provide comprehensive and } \\
\text { transparent information to (new) customers } \\
\text { to reduce concerns about cloud services }\end{array}$ & Pre-Adoption & Non-users & $\begin{array}{l}\text { Service/product } \\
\text { description using } \\
\text { simple terminology }\end{array}$ \\
\hline & $\begin{array}{l}\text { (R1.2) Adaptation of the service descriptions } \\
\text { in order to present the available services in a } \\
\text { user-friendly format }\end{array}$ & Pre-Adoption & Non-users & $\begin{array}{l}\text { Reducing technical } \\
\text { terms, presenting use } \\
\text { cases for available } \\
\text { services }\end{array}$ \\
\hline & $\begin{array}{c}\text { (R1.3) Provide assistance for } \\
\text { owners/managers to facilitate selection } \\
\text { decisions even under time-critical conditions }\end{array}$ & Pre-Adoption & Non-users & $\begin{array}{c}\text { Provide crucial } \\
\text { information about } \\
\text { service/product } \\
\text { highlights, give } \\
\text { comprehensive service } \\
\text { overviews }\end{array}$ \\
\hline \multicolumn{5}{|c|}{ Guideline 2: Provide trust-building instruments to reduce security and transparency concerns and enhance the reliability of cloud services } \\
\hline \multirow{4}{*}{$\begin{array}{l}\text { Security: } \\
\text { Concerns about general } \\
\text { security measures, data } \\
\text { privacy, data security, } \\
\text { encryption, and } \\
\text { availability } \\
\\
\text { Transparency: } \\
\text { Need for knowledge } \\
\text { about subcontracting } \\
\text { agreements, data center } \\
\text { location }\end{array}$} & $\begin{array}{l}\text { (R2.1) Provide extensive pre-sales support to } \\
\text { enhance trust and confidence }\end{array}$ & Pre-Adoption & $\begin{array}{l}\text { Non-users } \\
\text { Resisters }\end{array}$ & $\begin{array}{l}\text { Webinars, workshops, } \\
\text { free trials }\end{array}$ \\
\hline & $\begin{array}{l}\text { (R2.2) Reference to positive experiences } \\
\text { with services of existing cloud consumers to } \\
\text { demonstrate benefits }\end{array}$ & Pre-Adoption & $\begin{array}{l}\text { Non-users } \\
\text { Resisters }\end{array}$ & $\begin{array}{l}\text { Success story, white } \\
\text { paper }\end{array}$ \\
\hline & $\begin{array}{l}\text { (R2.3) Create more transparency through } \\
\text { detailed information and trustworthy } \\
\text { partners }\end{array}$ & $\begin{array}{l}\text { Pre-Adoption/ } \\
\text { Adoption }\end{array}$ & $\begin{array}{l}\text { Users } \\
\text { Non-users } \\
\text { Resisters } \\
\end{array}$ & $\begin{array}{l}\text { Invest in local data } \\
\text { centers, cooperate } \\
\text { with local partners }\end{array}$ \\
\hline & $\begin{array}{l}\text { (R2.4) Comprehensive communication of } \\
\text { applied (security) measures and procedures }\end{array}$ & $\begin{array}{l}\text { Pre-Adoption/ } \\
\text { Adoption/ } \\
\text { Post-Adoption }\end{array}$ & $\begin{array}{l}\text { Users } \\
\text { Non-users } \\
\text { Resisters }\end{array}$ & $\begin{array}{l}\text { Security management } \\
\text { system, easy to } \\
\text { understand SLAs }\end{array}$ \\
\hline \multicolumn{5}{|c|}{ Guideline 3: Create a specially trained support team to provide dedicated integration support } \\
\hline \multirow{3}{*}{$\begin{array}{l}\text { - Integration: } \\
\text { High effort of cloud } \\
\text { service integration into } \\
\text { existing IT } \\
\text { infrastructure and } \\
\text { business processes, lack } \\
\text { of standardization of } \\
\text { interfaces }\end{array}$} & $\begin{array}{l}\text { (R3.1) Provide extensive post-sales support } \\
\text { to assist in the integration of provided } \\
\text { services }\end{array}$ & Adoption & Users & $\begin{array}{l}\text { Dedicated contact } \\
\text { person for questions, } \\
\text { on-site training }\end{array}$ \\
\hline & $\begin{array}{l}\text { (R3.2) Enable and support step-by-step } \\
\text { integration }\end{array}$ & Adoption & $\begin{array}{l}\text { Users } \\
\text { Resisters }\end{array}$ & $\begin{array}{l}\text { Integration plan, } \\
\text { procedure model }\end{array}$ \\
\hline & $\begin{array}{l}\text { (R3.3) Provision and support of (standard) } \\
\text { interfaces }\end{array}$ & $\begin{array}{c}\text { Adoption/ } \\
\text { Post-Adoption }\end{array}$ & Users & $\begin{array}{l}\text { Q\&A, examples, } \\
\text { detailed interface } \\
\text { description }\end{array}$ \\
\hline \multicolumn{5}{|c|}{ Guideline 4: Provide a mechanism to enhance service reliability and reduce technical barriers } \\
\hline \multirow{3}{*}{$\begin{array}{l}\text { Vendor lock-in: } \\
\text { Concerns about vendor } \\
\text { dependency and, } \\
\text { consequently, limited } \\
\text { application possibilities } \\
\\
\text { Service reliability: } \\
\text { Need for guaranteed } \\
\text { permanent availability } \\
\text { and performance of the } \\
\text { cloud services }\end{array}$} & $\begin{array}{l}\text { (R4.1) Use standards and open formats to } \\
\text { reduce barriers to switching service } \\
\text { providers }\end{array}$ & Post-Adoption & $\begin{array}{l}\text { Users } \\
\text { Resisters }\end{array}$ & $\begin{array}{l}\text { Export/migration } \\
\text { tools, standard formats }\end{array}$ \\
\hline & $\begin{array}{l}\text { (R4.2) Enable interaction between multiple } \\
\text { cloud services and cloud service providers }\end{array}$ & Post-Adoption & $\begin{array}{l}\text { Users } \\
\text { Resisters }\end{array}$ & $\begin{array}{l}\text { Common interfaces, } \\
\text { app stores }\end{array}$ \\
\hline & $\begin{array}{l}\text { (R4.3) Cooperate with several network } \\
\text { providers to guarantee maximum availability }\end{array}$ & Post-Adoption & Users & $\begin{array}{c}\text { Transparent } \\
\text { demonstration of } \\
\text { cooperation network }\end{array}$ \\
\hline
\end{tabular}


phases of adoption and, partly, of post-adoption. CSPs can address these challenges by providing intensive support beyond the pre-adoption phase. On-site training, a detailed description of interfaces, and a dedicated contact person for the integration project are just a few examples of necessities for a successful integration.

The third guideline focuses on issues such as vendor lock-in and service reliability, which are mostly relevant in the post-adoption phase. CSPs should provide mechanisms for users to reduce technical barriers (e.g., export/migration tools, use standards) and to allow MEs to switch service providers more easily. To take a step forward in this direction, CSPs can profit from other benefits such as joining partner networks and participating in multicloud initiatives.

In sum, we derived four guidelines with a set of related recommendations, including concrete examples of how CSPs can adapt their business strategies to address the challenges of MEs. These guidelines are presented in Table 4.

\section{Conclusion and future research}

In the context of CC, cloud adoption, and MEs, we conducted a quantitative study in the first step to investigate the status of $\mathrm{CC}$ adoption among MEs (RQ1). Due to the specific characteristics of MEs (e.g., owner/manager is responsible for IT selections, little or no technical understanding, etc.), we were able to show that MEs cannot be characterized per se by a lower affinity to cloud services compared to larger companies. Only a few applications-customer relations management (CRM) and enterprise resource planning (ERP) systems, for example - are covered more extensively by cloud services in larger companies. The main arguments against using cloud services were concerns about security, provider dependency, and data privacy.

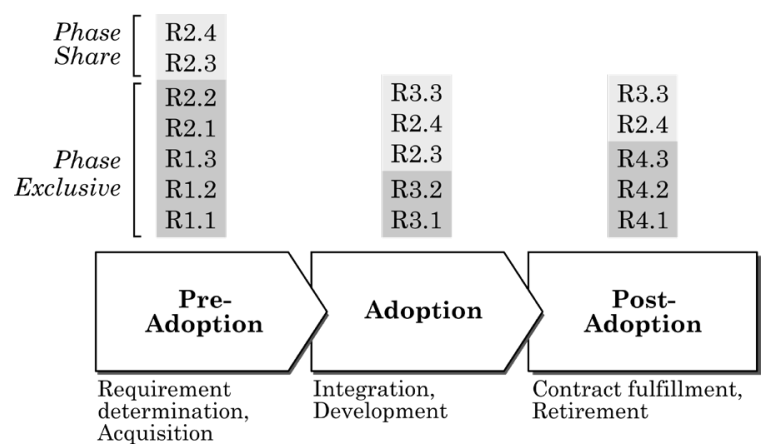

Figure 5: Recommendations with related phases
The most important motivating factors for using cloud services were location and device-independent access to documents and services, the flexibility of changing subscriptions, and cost savings. Based on the study results, we derived in a second step 13 recommendations through which CSPs can adapt their business strategies according to the respective adoption phases (see Figure 5).

Furthermore, we combined these recommendations into four guidelines, each addressing respective challenges for MEs on a meta level and providing action approaches for CSPs to adequately adapt their business strategies.

Our research contributes to practice and IS research. From a researcher's viewpoint, our paper provides a new study on cloud adoption by MEs and identifies important motivating factors for and against the use of CC. Although CC offers a wide range of benefits for companies of all sizes, companies with fewer than ten employees are often not considered or even completely excluded in existing studies of CC adoption (see Table 2). For practice/practitioners, our guidelines provide recommendations for CSPs that can be used for the design of an adapted business strategy by responding to the needs of MEs and meeting their specific requirements. CSPs can create incentives for this large customer group in order to counteract the competitive pressure among the constantly growing number of providers, thus reaching a new target group.

We argue that the developed guidelines are helpful to (re)define the business strategy of CSPs. This strategy should include the provision of adequate and comprehensible information, trust-building instruments, the reduction of technical barriers, and extensive pre-sales support during the pre-adoption and adoption phases. From a provider's perspective, taking these recommendations into account can shift MEs to the cloud.

Some limiting factors should be considered in future work. First, the derived guidelines may also apply to other classes of enterprises (e.g., SMEs) and are not limited only to addressing MEs. Second, the guidelines are not complete in their nature as they are based on the survey findings. A different method (e.g., a qualitative approach) or a different sample (e.g., another region) may result in further or divergent guidelines. Future research could also concentrate on the development of a cloud broker platform that considers both the cloud consumer perspective and the cloud service provider perspective in order to bring the two parties together. 


\section{References}

[1] Schneider, S., and A. Sunyaev, "Determinant factors of cloud-sourcing decisions: Reflecting on the IT outsourcing literature in the era of cloud computing", Journal of Information Technology 31(1), 2016, pp. 1-31.

[2] Hentschel, R., C. Leyh, and A. Petznick, "Current cloud challenges in Germany: the perspective of cloud service providers", Journal of Cloud Computing 7(1), 2018.

[3] Wulf, F., M. Westner, M. Schön, S. Strahringer, and C. Loebbecke, "Preparing for a Digital Future: Cloud Strategy at Continental AG", Proceedings of the 40st International Conference on Infomration Systems, ICIS, 2019.

[4] Eurostat (European Commission), Key figures on Europe, Luxembourg, 2018.

[5] Vithayathil, J., "Will cloud computing make the Information Technology (IT) department obsolete?", Information Systems Journal 28(4), 2018, pp. 634-649.

[6] Choudhary, V., and J. Vithayathil, "The Impact of Cloud Computing: Should the IT Department Be Organized as a Cost Center or a Profit Center?", Journal of Management Information Systems 30(2), 2013, pp. 67-100.

[7] Büst, R., and M. Hille, Multi-Cloud-Management im deutschen Mittelstand - Hybrid- und Multi-Cloud-Konzepte als Basis der digitalen Transformation, Crisp Research AG, Kassel, 2017.

[8] Heidkamp, P., and A. Pols, Cloud-Monitor 2018 Strategien für eine zukunftsorientierte Cloud Security und Cloud Compliance, KPMG AG, Köln, 2018.

[9] Nitze, A., A. Schmietendorf, K. Nadobny, and M. Kunisch, "Deutscher Mittelstand auf Wolke 7?", forcont business technology \& HWR Berlin, 2017.

[10] Venters, W., and E.A. Whitley, "A critical review of cloud computing: researching desires and realities", Journal of Information Technology 27(3), 2012, pp. 179-197.

[11] Yang, H., and M. Tate, "A Descriptive Literature Review and Classification of Cloud Computing Research.", Communications of the Association of Information Systems 31(2), 2012, pp. 35-60.

[12] Kappelman, L., E. McLean, V. Johnson, et al., "The 2016 SIM IT Trends Study", MIS Quarterly Executive 16(1), 2017, pp. 55-83.

[13] Tang, C., and J. Liu, "Selecting a trusted cloud service provider for your SaaS program", Computers \& Security 50, 2015, pp. 60-73.

[14] Mitra, A., N. O’Regan, and D. Sarpong, "Cloud resource adaptation: A resource based perspective on value creation for corporate growth", Technological Forecasting and Social Change 130, 2018, pp. 28-38.

[15] El-Gazzar, R.F., "A Literature Review on Cloud Computing Adoption Issues in Enterprises", In B. BergvallKåreborn and Nielsen P.A., eds., Creating Value for All Through IT. TDIT 2014. IFIP Advances in Information and Communication Technology, vol 429. Springer, Berlin, Heidelberg, 2014, pp. 214-242.

[16] Mell, P., and T. Grance, "SP 800-145. The NIST Definition of Cloud Computing", Special Publication (NIST SP), 2011.

[17] European Commission, Commission Recommendation of 6 May 2003 concerning the definition of micro, small and medium-sized enterprises, 2003.
[18] Federal Statistical Office of Germany, Shares of small and medium-sized enterprises in selected variables, 2018.

[19] Bley, K., C. Leyh, and T. Schäffer, "Digitization of German Enterprises in the Production Sector - Do they know how 'digitized' they are?", Proceedings of Twentysecond Americas Conference on Information Systems, AMCIS, 2016.

[20] Bharadwaj, A., O.A. El Sawy, P.A. Pavlou, and N. Venkatraman, "Digital Business Strategy: Toward a Next Generation of Insights", MIS Quarterly 37(2), 2013, pp. 471-482.

[21] McAfee, Navigating a Cloudy Sky - Practical Guidance and the State of Cloud Security, Santa Clara, 2018.

[22] Capgemini, Studie IT-Trends 2018, Berlin, 2018.

[23] Heidkamp, P., and A. Pols, Cloud Monitor 2017: Cyber Security im Fokus, KPMG AG, Köln, 2017.

[24] Schneider, S., and A. Sunyaev, "CloudLive: a life cycle framework for cloud services", Electronic Markets 25(4), 2015, pp. 299-311.

[25] Hevner, March, Park, and Ram, "Design Science in Information Systems Research", MIS Quarterly 28(1), 2004, pp. 75-105.

[26] Peffers, K., T. Tuunanen, M.A. Rothenberger, and S. Chatterjee, "A Design Science Research Methodology for Information Systems Research", Journal of Management Information Systems 24(3), 2007, pp. 45-77.

[27] Gregor, S., and A.R. Hevner, "Positioning and Presenting Design Science Research for Maximum Impact", MIS Quarterly 37(2), 2013, pp. 337-355.

[28] Gregor, S., and D. Jones, "The anatomy of a design theory", Journal of the Association for Information Systems 8(5), 2007, pp. 312-335.

[29] Aken, J.E. van, "Management Research Based on the Paradigm of the Design Sciences: The Quest for FieldTested and Grounded Technological Rules", Journal of Management Studies 41(2), 2004, pp. 219-246.

[30] Chandra, L., S. Seidel, and S. Gregor, "Prescriptive knowledge in IS research: Conceptualizing design principles in terms of materiality, action, and boundary conditions", Proceedings of 48th Hawaii International Conference on System Sciences, HICSS, 2015.

[31] Smeds, J., K. Nybom, and I. Porres, "DevOps: A Definition and Perceived Adoption Impediments", In C. Lassenius, T. Dingsøyr and M. Paasivaara, eds., Lecture Notes in Business Information Processing, vol 212. Springer, Cham, 2015, pp. 166-177.

[32] Godse, M., and S. Mulik, "An Approach for Selecting Software-as-a-Service (SaaS) Product", 2009 IEEE International Conference on Cloud Computing, 2009, pp. $155-158$.

[33] Cantele, S., and A. Zardini, "What drives small and medium enterprises towards sustainability? Role of interactions between pressures, barriers, and benefits", Corporate Social Responsibility and Environmental Management 27(1), 2020, pp. 126-136. 